\title{
Variation in BLM employee attitudes toward envi- ronmental conditions on rangelands
}

\author{
REBECCA T. RICHARDS AND LYNN HUNTSINGER
}

Rebecca T. Richards is research resource scientist with the Department of Agronomy and Range Science, University of California, Davis 95616. Lynn Huntsinger is assistant professor of range ecology with the Department of Environmental Science, Policy, and Management, University of California, Berkeley 94720.

\begin{abstract}
Using survey data collected as part of a comprehensive reevaluation of the Vale Rangeland Rehabilitation Project in eastern Oregon, this exploratory study examined variation in attitudes of Bureau of Land Management (BLM) employees toward rangeland environmental conditions. Almost one-half of the BLM employees surveyed believed the loss of streamside vegetation (48\%) and streambank erosion (42\%) were widespread problems on Vale rangelands. Approximately a quarter of the respondents believed rangeland soil loss $(24 \%)$ and overgrazing $(26 \%)$ were problems, while only a tenth believed water pollution (10\%) was a problem on many or most areas. A composite scale of these attitudes toward environmental conditions on rangelands was developed and assessed. The composite scale was regressed on respondents' regional affiliation, length of service, and ideological attitudes towards government role in natural resource management. In contrast to findings from studies for USFS employees, attitudes toward range environmental conditions were not determined by regional affiliation or length of service $(P>0.05)$. Rather, BLM employee attitudes toward range environmental conditions were found to vary by the interaction of length of service in the agency and attitude toward government's role in regulating water quality $(P<0.05)$ and managing livestock grazing $(P<0.01)$. As length of service increases, core beliefs, professional norms, or client constituencies may not polarize employee attitudes but rather moderate them over time. The accumulation of environmental knowledge may also tend to influence environmental attitudes so that ideological attitudes may have a weaker effect as time passes and expertise expands.
\end{abstract}

Key Words: attitudes, environmental conditions, professional norms, Bureau of Land Management

Effective resource management on public lands depends on the implementation of land management policies by government agencies (Mazmanian and Sabatier 1989). In the last decade, several policy studies have examined whether attitudes toward forest management vary among United States Forest Service (USFS) employees (McCarthy, Sabatier, and Loomis 1991, Brown and Harris 1992). To date, no studies have examined whether attitudes toward rangeland management differ among Bureau of Land Management (BLM) employees. Thus, we conducted this exploratory study to examine variation in attitudes of BLM employees toward rangeland environmental

\footnotetext{
Research was funded in part by the BLM. An early draft of this paper was presented at the 1993 Annual Meeting of the Society for Range Management in Albuquerque. The authors wish to thank Susan Durham, Andy Dyer, Jerry Holechek, and 2 annoymous reviewers for comments on earlier drafts.

Manuscript accepted 6 Mar. 1994.
}

conditions. For the study, we used survey data collected as part of a comprehensive reevaluation of the Vale Rangeland Rehabilitation Project in eastern Oregon (Huntsinger and Heady 1988). Like all previous studies examining natural resource agency personnel attitudes, this study did not correlate employee perceptions of environmental conditions with field measures. Because the objective of the study was to measure relative perceptions with actual environmental conditions held constant, we assessed respondents' attitudes about conditions on Vale rangelands during the same time period. While respondent attitudes did not vary over the duration of the study, the relative accura$c y$ of respondents' perceptions cannot be determined.

Several factors have been found to be associated with differences in USFS employee attitudes toward environmental issues. These include regional affiliation, length of service, and ideological and professional orientation (McCarthy, Sabatier, and Loomis 1991, Brown and Harris 1992). Do these general findings for USFS personnel hold for BLM employees? To our knowledge, only one study (Culhane 1981) has examined BLM employee attitudes toward environmental issues. Although Culhane's (1981) study found no significant general attitudinal differences between USFS and BLM employees on environmental issues, it did not examine possible variation among BLM personnel in specific attitudes toward environmental conditions on rangelands.

Using existing survey data for 2 separate groups of BLM employees, this study examined 1) whether attitudes toward environmental conditions differ between BLM employees of varying regional affiliations and lengths of service and 2) whether regional affiliation, length of scrvice, and ideological attitudes are important predictors of environmental attitudes.

\section{Methods}

\section{Survey Design}

In 1987, reevaluation of an 11-year (1962-1972) rangeland rehabilitation program in Malheur County, southwestern Oregon was conducted (Heady 1988). As part of this study, a pretested 16-page questionnaire was mailed to all BLM employees in the Vale district office in Malheur County in 1987. The survey design and administration followed Dillman's (1978) Total Design Method. Of the 77 Vale district BLM employees who received the questionnaire, 72 returned completed questionnaires for a response rate of $94 \%$ (Huntsinger and Heady 1988).

The same questionnaire was also distributed to BLM employees attending a BLM meeting during the annual Society for Range Management (SRM) meeting in Boise, Idaho in 1987. These BLM employees were from district BLM offices all over the United States. All BLM employees at the meeting were asked to complete and return the questionnaire as part of the program for the meeting. Although 
questionnaires were returned during the meeting, complete attendance records were not kept so that the response rate could not be determined. In all, 54 respondents were identified in this study as BLM employees from other districts.

All survey respondents were asked questions about the Vale district rangelands. Because many BLM training sessions occur on the district, the Vale Project is widely known and studied. Many of the respondents from other BLM districts reported that they were familiar enough with the Vale district to answer questions about it, and those who were not were excluded from analysis. In addition, missing or "don't know" responses to relevant items were excluded from analysis. Given these exclusions, the total sample size varied depending on the question and number of variables in the analysis. In all analyses, only cases with complete data were used.

\section{Independent Variables}

Regional affiliation was indicated by sample identification with lof the 2 survey groups (Vale BLM or other BLM). Respondents in both groups were asked if they had any responsibility in managing public lands and, if so, for how long. Responses to this question were used to indicate length of service which, for purposes of comparison to other studies, was dichotomized as 9 or fewer or 10 or more years. These 2 categories indicated less experienced and more experienced service respectively.

On a scale of 1 (strongly agree) to 5 (strongly disagree), respondents were asked to indicate their agreement with 5 statements concerning the role of government in natural resource management. These statements were 1) protecting water quality should be a government responsibility; 2) government regulation results in a loss of essential liberties and frcedoms; 3) the government has the right to regulate resource management on private lands; 4 ) the government has the right to determine the appropriate use of public lands; and 5) livestock grazing is the best use of public lands. These 5 statements were used as indicators of respondents' ideological attitudes.

\section{Dependent Variable}

Respondents were asked to rate the extent of various problems on the Vale district lands on a scale of 1 (not at all a problem), 2 (a problem in some areas), 3 (a problem in many areas), and 4 (a problem in most areas). Included in this list were following rangeland environmental conditions: 1) loss of streamside vegetation; 2) streambank erosion; 3) rangeland soil loss; 4) water pollution; and 5) overgrazing. A continuous scale of range environmental conditions was constructed as a sum of the scores for these 5 indicators for BLM employees. The scale comprised problem ratings ranging from 5 (no problem) to 20 (problem in most areas) for the 5 rangeland environmental conditions (streamside vegetation loss, streambank erosion, rangeland soil loss, water pollution, and overgrazing.) This composite attitude scale for range environmental conditions was then evaluated for internal reliability as a single scale using the statistical software SPSS. A factor analysis with orthogonal factor rotation indicated that all 5 attitude items comprised a single factor, and SPSS's reliability procedure obtained a Cronbach's alpha of 0.84 . Together, factor analysis and reliability analysis indicated that the internal reliability of the scale was high (McIver and Carmines 1988).

\section{Questionnaire Analysis}

Questionnaire data analysis was conducted in 2 stages. The first stage obtained descriptive statistics for the independent and dependent variables measured from the sample. The second stage assessed whether independent variables of regional affiliation, length of service, and ideological attitudes were related to the composite attitude scale for range environmental conditions. A two-way analysis of variance was performed to determine whether mean differences for the range environmental attitude scale existed among respondents grouped by regional affiliation and length of service. In addition, 5 multiple regression models were constructed for the composite scale with regional affiliation (Vale BLM $=1$ and other BLM $=0$ ) and length of service ( 9 or fewer years $=1$ and 10 or more years $=0$ ) as dichotomous dummy variables and each of the ideological attitudes as a single covariate. Each regression model included the main effect of both dummy variables and the two-way interaction effect between each dummy variable and the covariate. The three-way interaction effect between both dummy variables and the covariate was not included because of the relatively small sample size and the resulting lack of sufficient information to estimate additional parameters in a more complex model. In all models, only cases with complete data were used.

\section{Results}

For regional affiliation, $56 \%$ of the respondents were from the Vale district, and $44 \%$ were from other districts. For length of service, $60 \%$ had been BLM employees for 9 years or less, and $40 \%$ had been employees for 10 years or more. For each of the 5 ideological attitudes, respondent agreement varied from 1 (strongly agree) to 5 (strongly disagree). On average, respondents agreed that government should protect water quality (1.77 $\pm(0.07)$; mean \pm (standard error)). Respondents were generally neutral that government regulations result in a loss of essential liberties and freedoms $(3.14 \pm(0.09))$ and, on average, slightly disagreed that government has the right to regulate resource management on private lands $(3.81 \pm(0.10))$. Respondents agreed that government has the right to determine the appropriate use of public lands $(2.03 \pm(0.09))$ and were generally neutral that livestock grazing is the best use of public lands $(3.21 \pm(0.10))$.

Respondents' attitudes toward each of the 5 rangeland environmental conditions also varied from 1 (not at all a problem) to 4 (a problem on most areas). Almost one-half of the BLM employees surveyed believed the loss of streamside vegetation ( $48 \%$ ) and streambank erosion $(42 \%)$ were widespread problems on Vale rangelands. Approximately a quarter of the respondents believed rangeland soil loss $(24 \%)$ and overgrazing (26\%) were problems, while only a tenth believed water pollution ( $10 \%$ ) was a problem on many or most areas. Respondent scores on the composite integral scale of attitudes toward all five rangeland environmental conditions ranged from 5 (not at all a problem to 20 (a problem on most areas). In general, respondents believed all 5 environmental conditions on Vale rangelands together to be at least somewhat of a problem $(11.47 \pm(0.35))$.

The two-way analysis of variance detected no significant differences for regional affiliation or length of service on the mean responses of BLM employees on the environmental attitude scale. Neither regional affiliation $(P=0.23)$, length of service $(P=0.06)$, or the interaction of regional affiliation and length of service $(P=0.21)$ influenced BLM employee attitudes about range environmental conditions.

Although regional affiliation and length of service had no apparent direct effects on range environmental attitudes, both direct and indirect effects for length of service and ideological attitudes were obtained for 2 of the 5 multiple regression models. Where each of the 3 ideological attitudes toward government regulations are generalized political views (i.e., government regulations result in loss of liberties $(P=0.08)$, the government has the right to regulate private land $(P=0.11)$, and the government has the right to determine the use of public land $(P=0.09)$ ), neither regional affiliation, length of service, ideological attitudes, nor the two-way interactions produced significant regression coefficients $(P>0.05)$. However, the 2 ideological attitudes most related to government's role in range management (namely, that government should protect water quality and livestock grazing in the best use of the public land) produced regression models in which length of service and the ideological attitude covariate togeth- 
er predict significant differences in attitudes toward range environmental conditions.

Although regional affiliation differences appear to exist, these differences are not statistically significant for the model which included government's role in water quality (Table 1). Interpretation of these results therefore depends on the effects of length of service toward water quality regulation. As graphically depicted in Figure 1, less experienced BLM employees who agree that government should protect water quality tend to see more problems with range environmental conditions. Similarly, less experienced BLM employees who disagree that government should protect water quality tend to see fewer problems with range environmental conditions.

Table 1. Multiple regression model of attitude scale for range environmental conditions in Malheur County, Ore. (dependent variable) on regional affiliation, length of service, and ideological attitude toward government protecting water quality. See Figure 1 for fitted regression model.

\begin{tabular}{lcc}
\hline \hline Independent & $\mathrm{b}^{1}$ & $\mathrm{SE}^{2}$ \\
\hline Region $\dagger$ & -2.08 & 2.73 \\
Service & $5.35^{* *}$ & 1.81 \\
Water & -1.95 & 1.50 \\
Region x Water & 1.95 & 1.44 \\
Service x Water & $-2.04^{*}$ & 0.91 \\
$\mathrm{R}^{2}$ & 0.38 & \\
& $(\mathrm{n}=41)$ & \\
$\mathrm{F}_{5,35}$ & $4.41^{* *}$ & \\
\hline
\end{tabular}

Unstandardized regression coefficients

Unstandardized regression coefficients

t Region = regional affiliation; Service = length of service; Water = attitude that govern-

ment should regulate water quality; Reggession equation $Y=12.96+b_{R e g i o n}+$

${ }^{b}$ Service $+{ }_{\text {Water }+b_{\text {Rergion }}{ }^{*} \text { Water }}{ }^{+}{ }^{\text {Service }}$ *Water.

${ }^{*} P<0.05$

** $P<0.01$

Differences were also found for the regression model with length of service and respondents' attitudes toward livestock grazing on public lands (Table 2). Regional affiliation differences appear to exist, but these differences are not statistically significant. Interpretation is focused on length of service and attitude toward livestock grazing. As shown in Figure 2, attitudes of experienced employees toward range environmental conditions do not appear to change with their attitudes toward livestock grazing. This is in contrast to less experienced em-

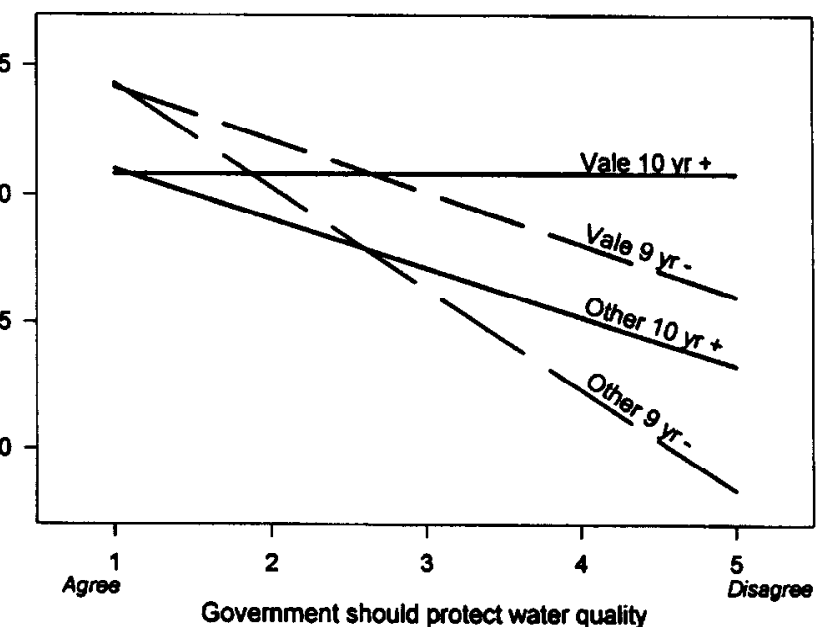

Fig. 1. Fitted regression model of attitude scale for range environmental conditions in Malheur County, Ore. on regional affiliation, length of service, and ideological attitude toward government protecting water quality. ployees' attitudes toward range conditions. Less experienced employees who agree that livestock grazing is the best use of public land tend to see fewer problems with range environmental conditions. Similarly, less experienced employees who disagree with livestock grazing tend to see more problems with range environmental conditions.

In summary, regional affiliation and length of service alone do not appear to influence attitudes toward range environmental conditions. Length of service in combination with some, but not all, ideological attitudes appears to influence BLM employee attitudes toward range environmental conditions.

Table 2. Multiple regression model of attitude scale for range environmental conditions in Malheur County, Ore. (dependent variable) on regional afinliation, length of service, and ideological attitude toward livestock grazing being the best the best use of public land. See Figure 2 for fitted regression model.

\begin{tabular}{lcc}
\hline \hline Independent & $\mathrm{b}$ & $\mathrm{SE}^{2}$ \\
\hline Region $\dagger$ & 0.53 & 4.85 \\
Service & $-6.00^{*}$ & 2.37 \\
Livestock & -0.23 & 1.56 \\
Region x Livestock & 0.24 & 1.57 \\
Service x Livestock & $2.11^{* *}$ & 0.67 \\
$\mathrm{R}^{2}$ & 0.40 & \\
& $(\mathrm{n}=41)$ & \\
$\mathrm{F}_{5,35}$ & $4.67^{* *}$ & \\
\hline
\end{tabular}

${ }_{2}$ Unstandaridzed regression coefficients

2 Standard errors of unstandardized regression coefficients

tRegion = regional affiliation; Service $=$ length of service; Livestock $=$ attitude that livestock grazing is the best use of public land; Regression equation is $Y=10.40+$ $b_{\text {Region }}+{ }^{\text {Service }}+{ }^{\text {Livestock }}+{ }_{\text {Rergion }}{ }^{*}$ Livestock $+{ }^{\text {Service*Livestock. }}$ $* P<05$ $* * P<01$

\section{Discussion and Conclusions}

Previous studies have addressed the question of attitudinal variation among natural resource agency personnel. Numerous studies have been conducted on the federal natural resource agencies in general (Clawson 1983, Dulhane 1981, Dana and Fairfax 1980, Durant 1992) and on USFS and its personnel specifically (Bond and Mawson 1968, Frome 1971, Kaufman 1960, Robinson 1975, Twight 1983, Kennedy and Quigley 1989, Twight and Lyden 1989, Brown and Harris 1992). In contrast to this study, regional differences have been found in USFS personnel attitudes toward clearcutting, developed recreation, prescribed fire, below-cost timber sales, timber primacy, and active environmental management in general (McCarthy, Sabatier, and Loomis 1991). Length of service differences have also been previously associated with USFS employee attitudes toward similar variables. Younger USFS employees with fewer years of service have been found to generally favor preserving the ecological integrity of the forests over producing forest goods and services (Brown and Harris 1992). In general, less experienced USFS employees also have been found to more strongly support increasing wilderness acreage, attending to environmental quality more than local employment, and preserving nature more than producing goods (McCarthy, Sabatier, and Loomis 1991).

Do these findings for USFS employee attitude differences hold for BLM employees? Different perceptions of rangeland environmental conditions among BLM employees would have significant implications for the implementation of rangeland resource management at the local and even national level. Because natural resource issues have become more important to the American public in the last decade (McCloskey 1992), federal agencies have faced increased scrutiny of their management of natural resources. Bureau of Land Management personnel may respond consistently to public scrutiny of range watershed, wildlife, and livestock issues if they perceive range resource 


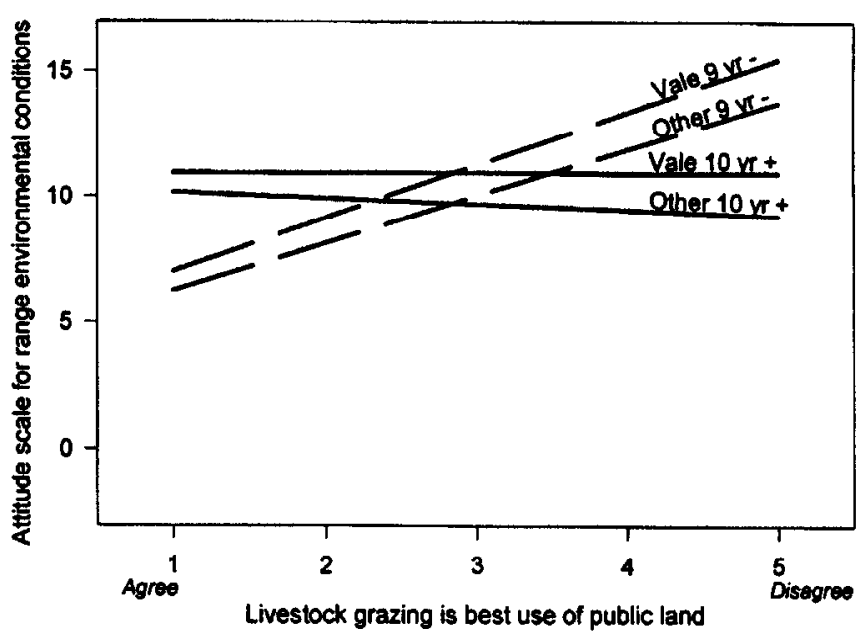

Fig. 2. Fitted regression model of attitudee scale for range environmental conditions in Malheur County, Ore. on regional affiliation, length of service, and ideological attitude toward livestock grazing on public land.

conditions similarly. Conflicting or ambiguous approaches to rangeland management may result if perceptions of environmental conditions on rangelands differ among BLM employees.

This study addressed how sociocultural factors affect the way rangeland conditions may be perceived and not the accuracy of BLM employee attitudes toward rangeland conditions. It is generally recognized that various methods developed by range science professionals for evaluating rangeland conditions are being challenged by scientists and practitioners both within and outside the profession (National Research Council 1993). In general, scientific methodologies are developed, implemented, and interpreted within a sociocultural context that will influence management outcomes. Decisions about "what is measured" to "what the measurement means" are subject to attitudes about what is important and what the goals of range condition assessment should be. Recognizing this, range scientists are now involving various rangeland stakeholders in the development of range condition assessment techniques and analyses as a way to improve the credibility and value of range condition assessments. Results of this study demonstrate that BLM employees are also influenced in their attitudes toward rangeland conditions by sociocultural factors shaped in part by their professional service and beliefs. This further supports the need to recognize the importance of understanding the dynamics of sociocultural influences on management decisions and planning.

Findings from this study support some but not all of the results of previous studies which have examined sociocultural differences in attitudes among USFS employees. Length of service does appear to affect BLM employee attitudes toward rangeland environmental conditions. However, experience only partially explains such differences. The findings here indicate that a strong interaction effect between length of service in the BLM and particular attitudes toward how government should manage natural resources may exist. Such interaction effects may support the argument that as employees become increasingly socialized in an agency, either strong professional norms (Twight 1983), client constituencies (Culhane 1991), or both (Fortmann 1990) may affect their views toward environmental conditions. Interaction effects between length of service and ideological attitudes may also help shape the core beliefs of employee coalitions within an agency, which in turn may affect the agency's policy implementation (Sabatier 1991).
As length of service increases, core beliefs, professional norms, or client constituencies may not polarize employee attitudes but rather moderate them over time. In addition, employee knowledge of range environmental conditions may accumulate as length of service increases. The accumulation of environmental knowledge may also tend to influence environmental attitudes so that ideological attitudes may have a weaker effect as time passes and expertise expands. If such dynamics between length of service and ideological attitudes do occur, important implications for how range management policy is implemented may exist as older employees retire and younger employees enter the agency. Variables affecting employee socialization, especially 1) the impact of mentoring within the agency, 2) frequent district transfers as part of expected career pathways, and 3) on-the-job training and experience, may affect range management policy implementation by the BLM, especially in the future.

\section{Literature Cited}

Bond, R.S. and J.C. Mawson. 1968. Some attitudes of students and professional foresters about forestry. J. Forest. 66:181-186.

Brown, G., and C.C. Harris. 1992. The U.S. Forest Service: Toward the new resource management paradigm? Soc. Nat. Res. 5:231-245.

Bultena, G.L. and J.C. Hendee. 1972. Foresters' views of interest group positions on forest policy. J. Forest. 80:337-342.

Clawson, M. 1983. The federal lands revisited. Resources for the Future, Washington, D.C.

Culhane, P. 1981. Public land politics. John Hopkins Univ. Press, Baltimore, Md.

Dana, S.T. and S. Fairfax. 1980. Forest range and policy: Its development in the United States. McGraw-Hill Book Co., New York, N.Y.

Dillman, D.A. 1978. Mail and telephone surveys: The total design method. John Wiley \& Sons, New York, N.Y.

Fortmann, L. 1990. The role of professional norms and beliefs in the agencyclient relations of natural resource bureaucracies. Nat. Res. J. 30:361-380.

Frome, M. 1971. The Forest Service. Praeger Publ., New York, N.Y.

Huntsinger, L. and H.F. Heady. 1988. Perceptions of the Vale Program p. 103-133. In: H.F. Heady (ed.), The Vale rangeland rehabilitation program: and evaluation. BLM Res. Bull. PNW-RB-157, Portland, Ore.

Heady, H.F. 1988. The Vale BLM District. In: H.F. Heady (ed.), The Vale rangeland rehabilitation program: An evaluation p. 1-18. BLM Resour. Bull. PNW-RB-157, Portland Ore.

Kaufman, H. 1960. The forest ranger. John Hopkins Univ. Press, Baltimore, Md.

Kennedy, J.J. and T.M. Quigley. 1989. How entry-level employees, forest supervisors, regional foresters and chiefs view forest service values and the reward system. Paper presented at the Sunbird Conference, Second Meeting of Forest Supervisors and Chiefs, Tucson, Ariz.

Mazmanian, D.A. and P.A. Sabatier.1989. Implementation and public policy (2nd Ed.). University Press of America, Lanham, Md.

McCarthy, C., P.A. Sabatier and J. Loomis. 1991. Attitudinal change in the Forest Service: 1960-1990. Paper presented at the 1991 Annual Meeting of the Western Political Science Association, Seattle, Wash.

McCloskey, M. 1992. Twenty years of change in the environmental movement: An insider's view, p. 77-88 In: R.E. Dunlap and A.G. Mertig (eds.), American environmentalism: The U.S environmental movement 1970-1990. Taylor and Francis, Philadelphia, Penn.

National Research Council. 1993. Rangeland health: New methods to classify, inventory, and monitor rangelands. National Academy Press, Washington, D.C.

Robinson, G.O. 1975. The Forest Service: A study in public land management. Resources for the Future, Washington, D.C

Sabatier, P.A. 1991. Toward better theories of the policy process. PS: Pol. Sci. \& Politics, June: 147-166

Twight, B.W. 1983. Organizational values and political power: The Forest Service versus Olympic National Park. Pennsylvania State Univ. Press, University Park, Penn.

Twight, B.W. and F.J. Lyden. 1989. Measuring Forest Service Bias. J. Forest. 87:35-41. 